\title{
Trajetórias de um pensador nômade: Gregório Baremblitt ${ }^{1}$
}

\section{Trayectorias de un pensador nómada: Gregório Baremblitt}

\section{Trajectories of a nomadic thinker: Gregorio Baremblitt}

\section{Domenico Uhng Hur*}

Universidade Federal de Goiás - UFG, Goiânia, Goiás, Brasil

\begin{abstract}
RESUMO
Este artigo tem como objetivo apresentar a complexa e ampla obra de Gregório Baremblitt, reconhecido analista institucional, esquizoanalista e esquizodramatista da América do Sul. Buscamos destacar os momentos e acontecimentos históricos em que se desenvolveram novas práticas e novos enunciados teóricos. Realizamos uma revisão bibliográfica em toda a sua obra e de pesquisas que traçaram sua história. Consideramos que há três etapas principais na trajetória de Baremblitt. A primeira, em que articula a relação entre psicanálise, marxismo e política. A segunda, quando se torna um dos principais pensadores da Análise Institucional. E a terceira, quando inventa em campo de saberes e intervenções klínico-psicossociais chamado de Esquizodrama, a criação mais intempestiva e original produzida a partir da Esquizoanálise.

Palavras-chave: esquizoanálise, esquizodrama, análise Institucional, psicanálise, política.
\end{abstract}

\begin{abstract}
In this article we present the complex and vast work of Gregorio Baremblitt, a renowned schizoanalist, schizodramatist and institutional analyst from South America. We emphasize the historical moments in which Baremblitt developed new practices and theories. We review his work and researches. We assume that there are three phases on his trajectory. First, when he articulates psychoanalysis, Marxism and politics; second, when he becomes one of the major thinkers of Institutional Analysis; and third, when he elaborates the field of knowledge and klinical-psychosocial interventions called Schizodrama, the most original invention produced from Schizoanalysis.

Keywords: schizoanalysis, schizodrama, institutional analysis, psychoanalysis, politics.
\end{abstract}

\section{RESUMEN}

Este artículo tiene como objetivo presentar la compleja y amplia obra de Gregorio Baremblitt, reconocido analista institucional, esquizoanalista y esquizodramatista de Sudamérica. Buscamos destacar los momentos y acontecimientos históricos en que se desarrollaron nuevas prácticas y nuevos enunciados teóricos. Realizamos una revisión bibliográfica en toda su 
obra y de las investigaciones que trazaron su historia. Consideramos que hay tres etapas principales en el trayecto de Baremblitt. La primera, en que articula la relación entre psicoanálisis, marxismo y política. La segunda, cuando se torna uno de los principales pensadores del Análisis Institucional. Y la tercera, cuando inventa el campo de conocimiento e intervenciones klínico-psicosociales llamado de Esquizodrama, la creación más intempestiva y original producida desde el Esquizoanálisis.

Palabras clave: esquizoanálisis, esquizodrama, análisis institucional, psicoanálisis, política.

\section{I ntrodução}

Apresentar o doutor Baremblitt em poucas páginas é um grande desafio; ainda mais considerando que nessas cinco décadas de atuação clínica e profissional produziu dezenas de obras, inumeráveis práticas e incontáveis alunos(as), admiradores(as) e sucessores(as) na América Latina. Portanto, o objetivo deste artigo é apresentar brevemente a obra do professor Baremblitt, destacando momentos históricos em que se desenvolveram novas práticas e enunciados teóricos. Este texto não tem a intenção de totalizar sua história, inúmeros feitos, nem citar todos seus trabalhos. Compreende-se que o artigo é apenas um recorte, uma redução, de seu amplo percurso. Mas um recorte que visa multiplicar e transmitir sua obra, principalmente aos estudiosos que não a conhecem. Como investigador implicado, traço a narrativa a partir de minha experiência com Gregório, tanto pessoal, e principalmente por mediação da literatura acadêmica ${ }^{2}$. Responsabilizo-me por qualquer equívoco inferencial que posso estar incorrendo.

Gregório Franklin Baremblitt é um psiquiatra nascido na Argentina, que migrou ao Brasil durante o regime da ditadura militar em seu país natal na década de 1970 . Sua trajetória pessoal, intelectual e profissional está intimamente relacionada às iniciativas e movimentos que participou; Gregório é um sujeito de grupos, de coletivos, de maltas. Participante e fundador de inúmeras associações dedicou sua vida ao fomento de formas mais potencializadas de vida, tanto no âmbito político, como clínico, culminando no seu invento mais potente, chamado de Esquizodrama. Introdutor da Esquizoanálise de Deleuze e Guattari em países como Brasil, Argentina e Uruguai, sua produção se estende a inúmeros campos: psicanálise, saúde mental, psicologia de grupos, análise institucional, socioanálise, política, esquizoanálise, esquizodrama, etc., em que assume posturas transdisciplinares e inventivas. Pode-se dizer que é um grande bricoleur, que de distintas articulações de campos diferentes, costuma produzir seus inventos. Pensador de imensa magnitude, é constantemente convidado para eventos e publicações de muitas associações em diversos temas. Para citar algumas, discussões sobre 
trabalho para o movimento sindical (FENAPSI - Federação Nacional dos Psicólogos) (Baremblitt, 1996), sobre a atualização da psicologia social para a Associação Brasileira de Psicologia Social - ABRAPSO (Baremblitt, 2001) e referentes à epistemologia, clínica, saúde mental e institucionalismo na importante coleção Saúdeloucura (Baremblitt, 1991b; 1994; 1997a; 1997b; 2003). Ao todo escreveu quinze livros e numerosos artigos para revistas científicas, periódicos e coletâneas.

A discussão será efetuada a partir de três estratos. O primeiro, o acontecimento histórico da ruptura ocasionada pelo grupo Plataforma. O segundo, sobre sua transição para o Brasil, em que se torna uma grande referência para o movimento denominado de Institucionalismo. E finalmente, quando cria um pensamento singular e original, que sintetiza e ultrapassa toda sua obra, com a criação do Esquizodrama.

\section{Psicanálise e política: plataforma para a transformação}

Baremblitt graduou-se em medicina em 1961 e se especializou em psiquiatria. Livre-docente em psiquiatria, pós-graduado em sociologia, fez toda a formação da famosa escola de Psicologia Social de Enrique Pichon-Rivière. Ingressou na Associação Psicanalítica Argentina - APA, tornando-se membro-candidato, em que chegou até o quarto ano de formação, momento da grande ruptura. Gregório foi um dos participantes de um momento instituinte e revolucionário no cenário das associações psicanalíticas; participou do Grupo Plataforma, da Argentina. Este foi um agrupamento de psicanalistas críticos e militantes, dentro da APA, que realizou a primeira cisão de uma associação de psicanálise por motivos políticos.

O movimento começou em 1969, em meio a efervescência social, política e desejante incitada pelos acontecimentos do maio de 68 . Durante um Congresso da Associação Internacional Psicanalítica IPA - em Roma, um grupo de jovens psicanalistas organizou um Fórum paralelo em que debateram questões que não eram tocadas pelo congresso oficial, como as críticas sobre: a formação do psicanalista; o significado, a estrutura e função das sociedades psicanalíticas; o papel social da psicanálise e sua imagem social; e as relações entre psicanálise e instituição. Do encontro, criaram uma comissão internacional para articular os diferentes grupos de trabalho (Kesselman, 1973, p. 247). Organizaram assembléias de discussão horizontalizadas, ao invés da tradicional estrutura vertical de poder das associações psicanalíticas. Mantiveram um caráter internacionalista e não nacional, ou regional.

Os sul-americanos, no caso os psicanalistas argentinos, eram muito ativos e passaram a ser reconhecidos pelo grupo Plataforma pelo caráter "anti-imperialista e anticapitalista que caracteriza o modo de 
luta de nossos povos" (Kesselman, 1973, p. 248). Tanto que o último encontro do Plataforma Internacional, ocorrido em paralelo ao Congresso da IPA de Viena em 1971, teve o bombástico título "A teoria e a prática psicanalítica à luz dos diferentes caminhos em direção ao socialismo". Entre as diversas discussões problematizou-se a inserção da atuação da psicanálise na reprodução da sociedade capitalista, bem como as bases ideológicas de suas práticas. Tal compreensão os levou a defender não apenas as insurgências dentro da instituição psicanalítica, mas o "compromisso dos psicanalistas com os povos empenhados em lutas de libertação" (Kesselman, 1973, p.248).

Após a primeira reunião em Roma, A. Bauleo e H. Kesselman, membros-candidatos da APA criaram o Plataforma Argentino (Rodrigues, Fernandes \& Duarte, 2001a), aglutinando outros membros que assumiam postura política mais crítica. Vale ressaltar que, diferente do que ocorreu no Brasil, muitos psicanalistas argentinos da APA assumiam um posicionamento crítico referenciados na leitura social marxista, em que temas como psicanálise e marxismo eram desenvolvidos (Bleger, 1958; 1973). Baremblitt (1973) nesse momento também assume como referência a postura marxista na crítica à psicanálise instituída reproduzida pelas suas associações tradicionais:

A crítica marxista é que pode contribuir com os autores para mostrar como a suposta ideologia da Psicanálise de que todos devemos compartilhar requer, para 'continuar revolucionária', no sentido restrito em que pode sê-lo, um exame do que aquela teve e tem de ruptura e compromisso com a sociedade real e a ideologia que a gerou, exame que deve ser feito a partir de um ponto de vista psicanalítico (intraciência), epistemológico (discriminativo entre ideologia e ciência) e também a partir de um político e ideológico definidos" (pp.172173).

O coletivo Plataforma Argentino, além de articular a psicanálise a outros campos de conhecimento, começou a questionar o modelo burguês e elitista de formação na APA, problematizando as práticas institucionais do cotidiano, o conservadorismo, os altos custos para se tornar psicanalista, etc. Passou a inserir literatura crítica e subversiva, característica de um pensamento insurgente da esquerda política. Nessa época os movimentos políticos revolucionários, como a guerrilha armada, estavam disseminados na América Latina (Castañeda, 1995), em que a transformação social era possível; a APA não poderia ficar incólume $a$ isso.

Entretanto, com as críticas e conflitos, a situação dentro da APA passou a ficar insustentável. O Plataforma Argentino não via mais 
sentido em continuar dentro da APA, por discordar de sua lógica de funcionamento. "Neste mesmo ano de 1971, precisamente a 4 de novembro, todos os membros do Plataforma Argentino apresentam renúncia formal à APA e à IPA através de uma declaração pública, na qual denunciam a ideologia burguesa da instituição oficial em todos os níveis de atividade: teórica, técnica, investigativa, didática e econômica" (Rodrigues, Fernandes \& Duarte, 2001b, p.142). Dezoito psicanalistas deixam a APA, sendo analistas didatas, membros titulares, associados e candidatos (como o caso de Baremblitt).

Vale lembrar que há um grande custo econômico em sair de uma sociedade psicanalítica, pois estas são legitimadas socialmente, em que há a cobrança de altos honorários e grande fluxo de indicação de clientes. Portanto, entende-se que para o Plataforma os princípios de autonomia política foram mais importantes do que os da acumulação econômica capitalista. Ao sair da APA, o Plataforma adotou um perfil mais interdisciplinar, intensificando a articulação da psicanálise com o marxismo, a análise institucional e outras correntes teóricas. Por exemplo, em 1973 Baremblitt introduz a Esquizoanálise na Argentina, ao fundar um grupo experimental que estudou a obra "O Anti-Édipo" (Deleuze \& Guattari, 1972).

O Plataforma Argentino foi diluído em 1974, com o receio de se transformar numa "IPA de esquerda". Havia aqueles que consideraram a dissolução como uma perda de uma oportunidade política, pois poderia ser fundada uma Escola, mas outros "creyeron que esta disolución abría el camino para uma difusión molecular de las ideas, de las intenciones, de los deseos y de las acciones de Plataforma" (Bauleo, 1990, p. 89). Decidiu-se pela segunda alternativa. Um recorte das idéias, reflexões e pensamentos psicanalíticos e políticos do Plataforma estão expressos nas coletâneas "Questionamos a psicanálise e suas instituições" volumes 1 e 2 (Langer, 1973; 1977), em que Baremblitt participou com dois textos, um sobre uma reflexão crítica sobre a obra freudiana (Baremblitt \& Matrajt, 1973) e outro discutindo as relações entre psicanálise, política e ideologia (Baremblitt, 1973). Gregório e outros plataformistas também contribuíram com o movimento de trabalhadores, criando o Centro de Docência e Investigação da Coordenadoria de Trabalhadores argentinos de Saúde Mental - CDICTSM, "que provavelmente tenha sido o maior movimento politizado de Trabalhadores de Saúde Mental do mundo" (Baremblitt, 1987a, p.50).

Poucos anos depois o cenário político na Argentina se complicou. "A partir de 1974, agentes da repressão estatal e paraestatal passam a perseguir membros do Plataforma e Documento. Comenta-se que nomes como Marie Langer, Armando Bauleo e Emilio Rodrigué, entre outros, estejam fazendo parte de 'listas negras' (Rodrigues et al., 2001a, p.135). Mesmo nesse cenário adverso Gregório fundou em 
Buenos Aires a Escola de Psicologia Freudiana e Socioanálise - EPFSO, assumindo já no título da Associação a extrapolação da psicanálise ao caminho da Análise Institucional. Ali se ensinava também a Esquizoanálise. Entretanto, as ameaças de bomba veiculadas pelos aparatos de repressão assustaram a equipe e os participantes, forçando o encerramento da experiência (Rodrigues et al., 2001b). A instauração da ditadura militar em 1976 acarretou numa repressão ainda mais intensa aos movimentos sociais, políticos, culturais e intelectuais no país. Com o recrudescimento da repressão pelos aparatos do estado, muitos ex-plataformistas tiveram que sair para o exílio. Brasil, México, I tália, Espanha, etc., foram exemplos de paísesdestino. Alguns dos companheiros, devido sua militância política, sofreram a violência de estado e estão "desaparecidos" até hoje (Bauleo, 1990). Em 1977, Baremblitt inicia seu exílio no Brasil. Gregório sintetiza seu trabalho deste período como: "Creo que mis principales actividades en Argentina se relacionan con el combate a la derecha en general (la psicoanalítica en especial) y contra la dictadura militar" (Baremblitt, 2013, p.1). Mesmo que já estivesse trabalhando com Análise Institucional e introduzido a Esquizoanálise na Argentina, categorizo esse primeiro momento de sua obra como "articulações entre psicanálise, marxismo, instituição e política", que foram o foco de suas discussões em seus artigos e livros, como por exemplo, "El concepto de realidad en psicoanálisis" (Baremblitt, 1974) e "Progressos e retrocessos em Psiquiatria e Psicanálise" (Baremblitt, 1978).

\section{Análise Institucional e desterritorialização: novas práticas no Brasil}

A migração de psicanalistas argentinos ao Brasil na década de 1970 foi de dois tipos (Coimbra, 1995; Rodrigues \& Barros, 2003). O primeiro, no início da década, foi de psicanalistas com uma perspectiva modernizadora, desenvolvimentista, de prevenção e grupalista, que correspondeu a demandas de formação psicanalítica. O segundo refere-se àqueles que vieram em detrimento da repressão da ditadura argentina e sua militância política de esquerda, com um enfoque freudomarxista, institucionalista, crítico e de caráter "plataformista". Como as associações psicanalíticas brasileiras assumiam um caráter conservador e elitista, as decorrências são claras. "A primeira geração era bem acolhida pelos hierarcas oficialistas da Psicanálise do Rio de Janeiro, a segunda só recebe, por parte deles, desqualificação e desprezo" (Rodrigues \& Barros, 2003, p. 65).

Baremblitt fez parte do grupo da 2o geração, exilando-se no Brasil. Rapidamente agregou-se a outros psicanalistas críticos brasileiros 
instaurando novas atividades e práticas que pudessem ser alternativas às práticas da IPA. Criou com alguns colegas o Núcleo de Estudos e Formação Freudiana - NEFF, onde lecionou por um curto período (Rodrigues, 2007). Organizou em 1978 com Chaim Samuel Katz e Luiz Fernando Mello Campos o Congresso de Psicanálise, Grupos e Instituições. Entre os conferencistas, Baremblitt (2013) destaca referências mundiais da Análise Institucional e da Psiquiatria Democrática, como Félix Guattari, Franco Basaglia, Robert Castel, E. Goffman, E. Rodrigué, S. Hite, T. Szasz, M. Langer, E. Pavlovsky, H. Kesselman, dentre outros. Participaram também dezenas de militantes da reforma psiquiátrica. "Ese congreso fue la primera visita de Guattari al país y se repitió a nuestro convite varias veces posteriormente" (Baremblitt, 2013, p.2).

Logo em seguida ao Congresso, fundaram o Instituto Brasileiro de Psicanálise, Grupos e Instituições - IBRAPSI. Ali “se enseñaba y practicaba grupalismo, análisis institucional, esquizoanálisis y esquizodrama. Esa institución trabajó durante seis años, en el transcurso de los cuales organizó varios congresos en los que estuvieron presente René Lourau, Gerard Mendel, A. Bauleo y muchas otras figuras importantísimas del ámbito de las Ciencias Sociales y de los movimientos micropolíticos revolucionarios" (Baremblitt, 2013, p.2). Gregório refere-se ao segundo simpósio internacional de psicanálise, grupos e instituições do IBRAPSI, que resultou na publicação do livro "O Inconsciente institucional" (Baremblitt, 1984).

Constata-se que o IBRAPSI enfatizou mais as referências da Análise Institucional (Rodrigues, 2007) e da Esquizoanálise do que as psicanalíticas, mas sem esquecer delas. E o mesmo movimento foi tomado pelas produções de Baremblitt que passaram a transitar mais no campo da Análise Institucional e da Esquizoanálise.

Vale ressaltar que a Esquizoanálise é um campo de conhecimento criado pelo filósofo Gilles Deleuze e pelo psicanalista-militante Félix Guattari na década de 1970 e que teve inúmeras influências no campo da Psicologia, seja nas práticas clínicas, nas intervenções sociais, nos modos de se compreender o mundo e o sujeito, etc. Deleuze e Guattari, no Anti-Édipo (1972/1976), enunciam três diferenças gerais com a psicanálise: o desejo não parte de uma falta originária, mas é positividade e produção; o delírio não é familiar, mas é histórico-universal; e o inconsciente não é figurativorepresentativo, mas sim pragmático-produtivo, atuando como uma usina de intensidades (Deleuze \& Guattari, 1980/1995). Para Baremblitt (1998) “o Inconsciente Esquizoanalítico estará pensado como um processo produtivo puro, não formado de representações nem de forças econômico-dinâmicas que mobilizam as representações ou papéis, seja de um Teatro ou de uma Linguagem, sendo como um incessante produzir caótico que, ademais, se produz 
a si mesmo e produz a realidade como renovados Todos" (p.114). Portanto, nessa perspectiva "o inconsciente extravasa, não cessa de se desterritorializar e não partilha da lógica da negatividade, mas sim das multiplicidades positivas e contínuas" (Hur, 2012a, p.20). Para conferir discussão mais detalhada e crítica acerca das diferenças entre Esquizoanálise e psicanálise, sugiro o livro "Psicoanálisis y esquizoanálisis: un ensayo de comparación crítica" (Baremblitt, 2004).

A originalidade e novidade instauradas pelo IBRAPSI fizeram com que houvesse uma grande procura pela associação. Houve intensa produção: "IBRAPSI organizó cinco congresos, publicó cinco libros de mi autoría, formó seis turmas de analistas institucionales y esquizodramatistas, atendió centenas de pacientes e intervino en varias organizaciones y movimientos" (Baremblitt, 2013, p.2). Devido a esses fatos, hierarcas das associações tradicionais da psicanálise brasileira passaram a atacar Baremblitt e seus colegas. Pode-se consultar o Jornal do Brasil de 10 de dezembro de 1979, de primeiro de fevereiro de 1980 e especialmente 4 de junho de 1980, no qual "Cabernite declara, no que foi então considerada uma clara alusão a Baremblitt e ao IBRAPSI: 'Uma ruidosa legião de psicopatas tomou de assalto a psicanálise' (Rodrigues, 2001, p. 166). Leão Cabernite foi presidente da Associação Brasileira de Psicanálise - ABP - e da Sociedade Psicanalítica do Rio de Janeiro - SPRJ - e também ficou conhecido por acobertar seu analisando, o membro-candidato da SPRJ, o médico Amílcar Lobo, das denúncias verídicas de que Lobo contribuiu nas sessões de tortura de presos políticos no período da ditadura militar brasileira (Coimbra, 1995; Rodrigues, 2001). Baremblitt afirma que as associações psicanalíticas reacionárias lançaram uma ofensiva contra o IBRAPSI, que além da publicação de artigos insultantes, "esse ataque culminou com uma série de agressões telefônicas aos diretores do IBRAPSI que incluíam advertências políticas, ameaças de morte e outras delicadezas" (1987a, p.52). Deve-se lembrar que ainda perdurava a ditadura militar no Brasil e havia comprovadamente um membro da SPRJ que atuou na equipe de torturadores do Estado.

Após alguns anos de existência e intensa produção, houve um declínio, refluxo de membros e conflitos que fizeram com o que o IBRAPSI encerrasse suas atividades. Discussão mais detalhada pode ser vista em Rodrigues (2001; 2002; 2007).

Nesse período, Gregório publicou muitos livros e foi colaborador assíduo das coleções Saúdeloucura e Lo Grupal. Lo grupal foi uma coletânea de diversos livros que discutiam psicanálise, política, análise institucional, etc. Foi organizada por ex-membros do Plataforma, muitos que regressaram à Argentina após o exílio. Baremblitt participou com temas como: ciência e epistemologia (1990), a problematização de conceitos e da Instituição-psicanálise 
(1983a; 1987b), grupo e modelos grupais (1987c; 1988) e o exílio (1983b). Nesse período, além dos já citados, são publicados os livros “Grupos: teoria e técnica" (1982), "Ato psicanalítico, ato político (1987a), "Cinco lições sobre a transferência" (1991a) e a grande referência para as disciplinas de Psicologia Institucional de todos os cursos de graduação de Psicologia do Brasil, "Compêndio de Análise Institucional e outras correntes", já reeditado inúmeras vezes e que fomenta os processos de autoanálise e autogestão (Baremblitt, 1986; 2002a). Vale citar também sua participação (Baremblitt, 1979) no livro "Psicanálise, poder e desejo" (Katz, 1979) e a obra "Lacantroças" (Baremblitt, 1991c), que de forma bem humorada critica e se despede da psicanálise de enfoque estruturalista.

Considero que o período de sua vinda ao Brasil e trabalho com o IBRAPSI é um momento em que tem uma produção exuberante em Análise Institucional, tornando-se um dos principais pensadores do campo. É um dos pólos de articulação na América Latina com pensadores como René Lourau, Gerard Mendel, Félix Guattari, dentre outros. Nas suas análises, as obras de G. Deleuze e F. Guattari, R. Lourau, M. Foucault, etc., são fundamentais, mas ouso afirmar que aí ainda não é seu apogeu, não é onde atinge seu maior grau de singularização. Este foi um período rico de produção e reflexão que foi etapa transicional para a criação de seu mais original invento, 0 Esquizodrama.

\section{Esquizodrama: momento da transmutação}

Após a dissolução do IBRAPSI Gregório estabeleceu residência na cidade de Belo Horizonte, em Minas Gerais, onde vive até hoje. Realiza palestras, cursos e sessões de Esquizodrama em diversas localidades, como Argentina, Uruguai, Lisboa, Barcelona, Bolonha, Caracas, São Paulo, Rio de Janeiro, Minas Gerais, etc. Foi professor convidado de universidades como UFMG, PUC-MG, UERJ, PUC-RJ, etc. Teve participação de destaque em várias edições do "Congreso de las Madres de Plaza de Mayo", sendo nomeado Doutor Honoris Causa por essa importante associação militante pelos Direitos Humanos e pela memória na Argentina.

Fundou em 1995 uma nova associação, o Instituto Félix Guattari, um local de formação e experimentação e intervenção klínica e política. Gregório quis fazer uma homenagem a esse importante protagonista da Esquizoanálise, que costumeiramente é deixado em segundo plano pelos acadêmicos, quando comparado ao filósofo Gilles Deleuze. Tal fato é tão injusto, principalmente se considerarmos que as principais teses defendidas no Anti-Édipo (Deleuze \& Guattari, 1972) são decorrências de material bruto de Guattari, que foi "lapidado" por Deleuze (Dosse, 2010). 
Nessa década Gregório publicou um fino mas portentoso livro, intitulado "Introdução à Esquizoanálise" (Baremblitt, 1998) e obras sobre um novo e inédito campo de conhecimento e intervenção, chamado de Esquizodrama. Aparece um novo Baremblitt, não mais como pensador que utiliza conceitos esquizoanalíticos como uma caixa de ferramentas (Foucault \& Deleuze, 1979), mas um Baremblitt que passa a criar um grande arsenal de instrumentos conceituais e uma nova ontologia. Através de suas práticas klínicas, agora com $\mathrm{k}$, para indicar clínica como klinos e klinamen, ou seja, a klínica como encontro de diferenças e produção de desvio, de transformação, passa a operar os conceitos filosóficos da Esquizoanálise enquanto práxis. Tal como Antonin Artaud com seu Teatro da Crueldade, Baremblitt com seus múltiplos dispositivos desterritorializa as formações molares e coercitivas-edípicas do sujeito, que bloqueiam o desejo e despotencializam a vida trazendo à tona intensidades assignificantes que vão além de qualquer formação discursiva. Opera uma desconstrução identitária e dos mecanismos defensivos que levam o sujeito ao contato com seu inconsciente molecular, numa efetiva produção de um corpo sem órgãos (Artaud, 1947; Deleuze \& Guattari, 1980), fluido, pleno, potente. As klínicas do Esquizodrama buscam detectar as resistências e bloqueios que o sujeito ou 0 coletivo se deparam "para fomentar processos de intensificação dos fluxos desejantes com o intuito de levar à produção, à criação e à afirmação do desejo" (Hur, 2012a, p.24).

Passa a utilizar uma série de neologismos para expressar novos processos, novos acontecimentos e conceitos. Os conceitos agora recebem o nome de esquizoemas: "unidades semióticas del discurso y de la acción esquizoanalítica" (Baremblitt, 2004, p.201). O cosmos seguro e determinado em que vivemos torna-se Caosmos, funcionando mais por processos de diferenciação e variação contínua, ao invés da identidade e estabilidade. A realidade define-se mais pela heterogeneidade, do que uma suposta e idealizada homogeneidade, dividindo-se agora em três superfícies em que ocorrem processos distintos: produção, registro-controle e consumação. À realidade, articula-se a realteridade; o ser dá lugar ao devir (Baremblitt, 1998). Dessa forma, o Esquizodrama visa operar na superfície de produção, intensificando os fluxos desejantes, os devires e acontecimentos, em que há uma relação de imanência entre desejo e produção. Todo desejo é produtivo, como toda produção é desejante. Para tanto, deve realizar uma raspagem das estruturas coercitivas, tanto materiais como psíquicas, da superfície de registro-controle, que possam barrar o movimento e o desejo. A moral, as normas, o superego, o complexo de Édipo, ou mesmo a psicologia e a psicanálise podem ter essa função de bloqueio das potências desejantes. Por isso os dispositivos klínicos do Esquizodrama configuram-se como uma máquina de guerra, que visa desconstruir os "equipamentos com os 
quais a maquinaria repressiva tende a reprimir, eliminar ou capturar as singularidades produtivo-desejantes" (Baremblitt, 1998, p.55). A máquina de guerra é um conceito criado por Deleuze e Guattari (1980) para expressar uma máquina abstrata que adota um potencial instituinte, de desterritorialização, tendo "uma independência em relação à captura, à conservação e à sobrecodificação do aparelho de Estado, estando mais ligada à conformação de algo mutante, que no seu prosseguir se transforma e se metamorfoseia" (Hur, 2012b, p.56). Portanto, concomitante à raspagem das estruturas coercitivas, intensifica-se os processos produtivos-desejantes caósmicos, que Baremblitt (2004, p.248) nomeia como Esquizoonte.

Se para Deleuze e Guattari (1992) a Filosofia é a arte de criar conceitos, o Esquizodrama é a arte de criar múltiplos dispositivos de intervenção (Baremblitt, 2002b), sejam klínicos, educativos, sociais, etc. Baremblitt nos ensina que o esquizodrama funciona como um conjunto heterogêneo de estratégias, táticas e técnicas "que busca atuar sobre os aspectos subjetivos, sociais, semióticos e tecnológicos de seus dispositivos para proporcionar experiências de desterritorialização dos agenciamentos instituídos, para dar circulação e trânsito aos fluxos (psíquicos, corporais, grupais, sociais) codificados, fomentar processos de criação e estéticos, efetuando assim acontecimentos, novos regimes de signos e processos de singularização" (Hur, 2013, p.271). Baremblitt, busca assim incitar e fomentar nos participantes do Esquizodrama os atos dionisíacos e criadores dos pensamentos, afetos e ações.

Há distintos dispositivos de intervenção utilizados, com enquadres e consignas móveis, que empregam não apenas recursos verbais, mas também corporais, artísticos e dramáticos que se referenciam de distintas correntes teóricas, tal como da esquizoanálise, psicodrama, bioenergética, psicanálise e até de rituais como da Umbanda. Tal referência inusitada inspira-se na experiência de G. Lapassade na África e no Brasil, em que a partir de sua participação em rituais de Umbanda e Vodu, levou as experiências de transe para a clínica, criando a Transeanálise (Lapassade, 1980). “Portanto, há distintos agenciamentos maquínico-corporais nos diferentes dispositivos, em que pode haver a situação face-a-face grupal, ou da performance psicodramática dos atores em cena, ou até de uma dança com tambores tribais, que aparentemente pode parecer ser uma experiência caótica" (Hur, 2012a, p.23). Baremblitt (2002b) nomeia cinco tipos de klínicas: a) da produção, reprodução e anti-produção; b) do Caos, Cosmos, Caosmos; c) da diferença-repetição; d) do acontecimento-devir e; e) da Multiplicação dramática. E tal como Pichon-Rivière (1986) com o dispositivo do grupo operativo, Baremblitt sustenta que o Esquizodrama pode ser trabalhado em inúmeros e diversificados campos: na intervenção social, educação, psicoterapia, saúde mental, artes, etc. Então, o Esquizodrama é uma 
caixa de ferramentas que potencializa os efeitos da Esquizoanálise, que de acordo com Baremblitt (1998), "é uma máquina fundamentalmente energética, destinada a vibrar e a fazer vibrar aqueles que dela se aproximam e a engajá-los em um movimento produtivo, que não passa exatamente pelas ideias nem pelas palavras, passa pelos afetos" (p.14).

Gregório logrou êxito em transformar diversos conceitos filosóficos esquizoanalíticos em dispositivos klínicos esquizodramáticos. Criou inúmeros dispositivos que fomentam a produção desterritorializante de um corpo sem órgãos (Deleuze \& Guattari, 1980), através de práticas corporais, como a bioenergética e a respiração holotrópica. Produziu rizomas (Deleuze \& Guattari, 1980) humanos com seus esquizodramatizados em sessões de Multiplicação Dramática (Kesselman \& Pavlovsky, 1991), como variadas linhas de fuga no processo psicoterápico, que rompem com as formações molares e codificadas dos sujeitos.

Cito um exemplo. Deleuze e Guattari escreveram um texto intitulado "Rostidade" (1980) em que criticam a codificação da face, de como ela se torna a identidade do corpo, reduzindo assim sua multiplicidade de afecções e possibilidades. Também criticam, do ponto de vista social, a constituição de um rosto que se torna padrão, que se torna norma, que é a representação pictórica de Jesus Cristo, face que expressa o homem macho ariano civilizado de traços finos. Devido a tal crítica, Gregório criou um dispositivo klínico que visa a desterritorialização dessa face codificada e instituída, a partir de um jogo com espelhos, imagens e luminosidades: o dispositivo da "Rostridad". Utiliza um espelho especial que ao mesmo tempo reflete e refrata a imagem. Coloca assim duplas de pessoas face-a-face com o espelho entre elas. Em um ambiente semicerrado e de acordo com as variações de iluminação sobre o espelho resulta-se no assombroso fenômeno imagético de conjunção das faces. De tal forma que Gregório busca intensificar os distintos afetos de estranheza que emergem da configuração imagética facial mais bizarra para a dupla, trazendo assim à tona um afeto ainda não significado, ou melhor, um aspecto assignificante. A consigna é que tal aspecto deve ser ainda mais intensificado e objeto de um processo de figuração, seja por via de uma dramatização, um jogo de palavras, uma poesia, um desenho, etc. Emergem assim múltiplos sentidos para a experiência, que às vezes são verbalizados, outras vezes não, sempre abrindo para o campo da indeterminação e novidade em que há uma produção intensiva de sentidos para a experiência vivida.

Um aspecto que merece ser citado é que o Esquizodrama não se constitui como um campo de conhecimentos e práticas consolidado, de dispositivos e técnicas com consignas, tarefa e enquadre fixos e delimitados. Caracteriza-se mais como variação contínua e convite à inventividade de novos dispositivos e práticas. É mais uma 
experimentação do que aplicação, num saber instituinte, ao invés de algo pressuposto e fechado.

Recentemente, como homenagem de seus associados a Gregório, o Instituto Félix Guattari recebeu o novo nome de Fundação Gregório Baremblitt. Também foi formada outra Fundação Gregório Baremblitt na cidade de Uberaba/MG, bem como o Instituto Gregório Baremblitt na cidade de Frutal/MG. Estas associações, além de oferecerem cursos e realizarem intervenções klínicas e sociais, fazem parcerias com outras de Montevidéu, Argentina, Portugal e Canadá, as quais organizam os congressos internacionais de Esquizoanálise e Esquizodrama, que já contam com quatro edições. A Fundação de Belo Horizonte está em sua nona turma no curso de pós-graduação lato sensu de Esquizoanálise, Esquizodrama e Análise Institucional. A Fundação de Uberaba conta também com um dispositivo de saúde mental, o Centro de Atenção Psicossocial - CAPS - Maria Boneca, "que atende trezentos e setenta pacientes com esquizodrama todos os dias" (Baremblitt, 2013, p.3). Ressalta-se que este CAPS funciona com todos os princípios da Reforma psiquiátrica, seguindo a autoanálise e a autogestão, tanto que seu nome foi dado por um dos usuários do serviço. Para conferir algumas reflexões klínicoinstitucionais que resultaram da experiência sugiro o livro "Lembranças da loucura" (Bichuetti, 1999). A Fundação de Frutal também conta com um projeto social educativo, um curso prévestibular dirigido a alunos de baixa renda, intitulado Cursinho Popular Gregório Baremblitt, que tem como finalidade democratizar o acesso à Universidade.

\section{Considerações finais}

Neste ensaio busquei apresentar brevemente o percurso de Gregório Baremblitt, salientando três etapas principais pelas quais transitou: Psicanálise e política, Análise Institucional e Esquizoanálise e Esquizodrama. O primeiro momento quando participou das reflexões críticas entre psicanálise, marxismo e política com o coletivo Plataforma Argentino; o segundo, quando se tornou um dos protagonistas da Análise Institucional no Ocidente; e o terceiro, quando criou o dispositivo mais criativo relacionado à Esquizoanálise: - Esquizodrama. A invenção do Esquizodrama marca a obra de Baremblitt como o momento em que ele realmente assume um "nome próprio", quando se torna um "autor" e passa a falar por seu nome, pois cria um novo regime de enunciados e práticas original e singular. Não se restringe a reproduzir ou aplicar conceitos da Esquizoanálise, mas sim a produzir novos conceitos, instrumentos e máquinas abstratas que fomentam processos de desterritorialização e 
transformação. Seguramente, o Esquizodrama é o invento mais intempestivo e original produzido a partir da Esquizoanálise.

Ademais, Baremblitt (2013) considera que o resgate e estudo de sua obra "tiene sentido en el seno de la lucha entre la difusión revolucionaria de Esquizoanálisis y su recuperación por el establishment" (p.3), pois denuncia que há posições teórico-práticas que apaziguam o potencial disruptivo da Esquizoanálise com finalidades econômicas e de captura de sua insurgência, enfim, com finalidades que corroboram com a axiomática capitalista (Deleuze \& Guattari, 1972).

Ao longo de toda sua carreira, Gregório se mantém crítico e contestador, mesmo de experiências que participou: "Gregorio Baremblitt relata ter sido convidado, pelos organizadores, a enviar um artigo destinado a livro comemorativo dos 25 anos do Grupo Plataforma. A tonalidade bastante crítica de seu texto teria levado ao cancelamento da publicação como um todo" (Rodrigues, 2004, p.30). Ou seja, seu texto não foi publicado para não inviabilizar a coletânea de trabalhos. Então, ao invés de manter postura ufanista acerca de tal acontecimento, prefere manter compromisso com a crítica do instituído.

Para finalizar, considero que Baremblitt com suas teorias e práticas figura como uma máquina de guerra (Deleuze \& Guattari, 1980). Gregório é a expressão de um pensador e klínico nômade, sempre em movimento, compromissado com a transformação, os fluxos desejantes, um novo mundo, novos sujeitos e na realização de uma Utopia Ativa. E nos deixa com uma maquinaria conceitual e de intervenção klínico-social, o Esquizodrama, que é um convite para que possamos exercer a inventividade da potência de nossos pensamentos para criar novas práticas, novos regimes de enunciados e processos de subjetivação.

\section{Referências}

Artaud, A. (1947) Para acabar com o juízo de Deus. Emissão radiofônica. Recuperado em 8 agosto, 2013, de http://escolanomade.org/images/stories/biblioteca/downloads/a rtaud-para-acabar-com-o-julgamento-de-deus. pdf

Baremblitt, G.F. (1973). Psicanálise, ideologia e política. In M. Langer (org.). Questionamos a psicanálise e suas instituições (pp.143177). Petrópolis, RJ : Vozes.

Baremblitt, G.F. (1974). El concepto de realidad em psicoanálisis. Buenos Aires: Argentina: Ed. Socioanálisis.

Baremblitt, G.F. (1978). Progressos e retrocessos em Psiquiatria e Psicanálise. Rio de Janeiro, RJ: Global. 
Baremblitt, G.F. (1979). Ciência, poder e desejo. In C.S. Katz. Psicanálise, poder e desejo (pp.116-132). Rio de Janeiro, RJ: IBRAPSI.

Baremblitt, G.F. (org.) (1982). Grupos: teoria e técnica. Rio de Janeiro, RJ: Graal.

Baremblitt, G.F. (1983a). La institución del psicoanálisis. Su panorama actual, su crisis y su futuro. Lo Grupal 1 (pp.51-64). Buenos Aires: Argentina: Búsqueda.

Baremblitt, G.F. (1983b). El exílio: verificación o no de las teorías y técnicas terapéuticas. Lo Grupal 1 (pp.71-74). Buenos Aires: Argentina: Búsqueda.

Baremblitt, G.F. (org.) (1984). O inconsciente institucional. Petrópolis, RJ : Vozes.

Baremblitt, G.F. (1986). Compêndio de Análise Institucional e outras correntes. Rio de Janeiro, RJ : Rosa dos Tempos.

Baremblitt, G.F. (1987a). Ato psicanalítico, ato político. Belo Horizonte, MG: Segrac.

Baremblitt, G.F. (1987b). Repaso de las formas de abordar la cuestión edipiana en psicoanálisis. Lo Grupal 4 (pp.21-58). Buenos Aires: Argentina: Búsqueda.

Baremblitt, G.F. (1987c). Revisión sintética y comentarios acerca de los modelos grupales. Lo Grupal 5 (pp.67-90). Buenos Aires: Argentina: Búsqueda.

Baremblitt, G.F. (1988). Notas acerca de un posible programa de investigación el psicoanálisis y lo grupal en Argentina 1988. Lo Grupal 6 (pp.55-70). Buenos Aires: Argentina: Búsqueda.

Baremblitt, G.F. (1990). Acerca de las virtudes teologales, las ciencias y las locuras. Lo Grupal 8 (pp.53-81). Buenos Aires: Argentina: Búsqueda.

Baremblitt, G.F. (1991a). Cinco lições sobre a transferência. São Paulo, SP: Hucitec.

Baremblitt, G.F. (1991b). As virtudes teologais, das ciências e das loucuras. Saúdeloucura, n.2 (pp.93-120). São Paulo, SP: Hucitec.

Baremblitt, G.F. (1991c). Lacantroças. São Paulo, SP: Hucitec.

Baremblitt, G.F. (1994). Apresentação. Saúdeloucura, n.4 (pp.3-20). São Paulo, SP: Hucitec.

Baremblitt, G.F. (1996). Trabalho e subjetividade. In Federação nacional dos Psicólogos - FENAPSI (org.) O trabalho na sociedade contemporânea - desafios e perspectivas (pp.43-49). Belo Horizonte, MG: Sindicato dos psicólogos de Minas Gerais PSIND.

Baremblitt, G.F. (1997a). A clínica como ela é: dez pontos para uma apresentação. Saúdeloucura, n.5 (pp.5-10). São Paulo, SP: Hucitec. 
Baremblitt, G.F. (1997b). Por uma nueva clinica para el poliverso psy. Saúdeloucura, n.5 (pp.11-30). São Paulo, SP: Hucitec.

Baremblitt, G.F. (1998). Introdução à Esquizoanálise. Belo Horizonte, MG: Instituto Félix Guattari.

Baremblitt, G.F. (2001). Manifesto para uma atualização da Psicologia Social. In Abrapso-Sul (org.). Psicologia Social: estratégias, políticas e implicações (pp.159-164). Santa Maria, RS: Abrapsosul.

Baremblitt, G.F. (2002a). Compêndio de Análise Institucional e outras correntes: Teoria e prática. Belo Horizonte, MG: Instituto Félix Guattari, 5a edição.

Baremblitt, G.F. (2002b). Dez proposições descartáveis acerca do esquizodrama (mimeo.). Recuperado em 8 agosto, 2013, de http: //artigosgregorio. blogspot.com.br/2008/02/dez-proposiesdescartveis-acerca-do.html

Baremblitt, G.F. (2003). Quem acredita na utopia ativa? Saúdeloucura, n. 8 (pp.9-20). São Paulo, SP: Hucitec.

Baremblitt, G.F. (2004). Psicoanálisis y esquizoanálisis (un ensayo de comparación crítica). Buenos Aires: Argentina: Asociación Madres de Plaza de Mayo.

Baremblitt, G.F. (2013). Entrevista ao autor. [Mimeo]. Fundação Gregório Baremblitt, Belo Horizonte/Minas Gerais, Brasil.

Baremblitt, G.F. \& Matrajt, M. (1973). O estudo da obra de Freud. In M. Langer (org.). Questionamos a psicanálise e suas instituições (pp.116-136). Petrópolis, RJ : Vozes.

Bauleo, A. (1990). Plataforma hoy. Grupalidad em dispersión. Lo Grupal 8 (pp.85-92). Buenos Aires: Argentina: Ediciones Búsqueda.

Bichuetti, J. (1999). Lembranças da Loucura. Belo Horizonte, MG: Instituto Félix Guattari.

Bleger, J. (1958). Psicoanálisis y dialéctica materialista. Buenos Aires: Argentina: Paidos.

Bleger, J. (1973). Psicanálise e marxismo. In M. Langer (org.). Questionamos a psicanálise e suas instituições (pp.17-37). Petrópolis, RJ: Vozes.

Castañeda, J. (1995). La utopía desarmada - Intrigas, dilemas y promesa de la izquierda en América Latina. Barcelona: Espanha: Ariel.

Coimbra, C. (1995). Guardiães da ordem: Uma viagem pelas práticas psi no Brasil do "Milagre". Rio de Janeiro, RJ: Oficina do Autor.

Deleuze, G. \& Guattari, F. (1972/1976). O Anti-Édipo. Rio de Janeiro, RJ: I mago.

Deleuze, G. \& Guattari, F. (1980/1995). Mil Platôs: Capitalismo e Esquizofrenia, Vols. 1 a 5. São Paulo, SP: Ed. 34.

Deleuze, G. \& Guattari, F. (1992). O que é a Filosofia? São Paulo, SP: Ed. 34. 
Dosse, F. (2010). Gilles Deleuze \& Félix Guattari: Biografia cruzada. Porto Alegre, RS: Artes médicas.

Foucault, M., \& Deleuze, G. (1979). Os intelectuais e o poder. In M. Foucault. Microfísica do Poder (pp.69-78). Rio de Janeiro, RJ: Graal.

Hur, D.U. (2012a). O dispositivo de grupo na Esquizoanálise: tetravalência e esquizodrama. Vínculo. 9(1), 51-69. Recuperado em 8 agosto, 2013, de http: //pepsic. bvsalud.org/pdf/vinculo/v9n1/a04.pdf

Hur, D.U. (2012b). Cartografias da luta armada: a guerrilha como máquina de guerra. Mnemosine , (2), 18-26. Recuperado em 8 agosto, 2013, de http: //www.mnemosine.com.br/ojs/index.php/mnemosine/articl e/view/254/pdf_239

Hur, D.U. (2013). Esquizoanálise e política: proposições para a Psicologia Crítica no Brasil. Teoría y crítica de la psicología, 3, 264-280. Recuperado em 8 agosto, 2013, de http: //teocripsi.com/documents/3HUR.pdf

Katz, C.S. (1979). Psicanálise, poder e desejo. Rio de Janeiro, RJ: IBRAPSI.

Kesselman, H. (1973). Plataforma Internacional: Psicanálise e AntiImperialismo. In M. Langer (org.). Questionamos a psicanálise e suas instituições (pp.246-250). Petrópolis, RJ: Vozes.

Kesselman, H., \& Pavlovsky, E. (1991). A Multiplicação Dramática. São Paulo, SP: Hucitec.

Langer, M. (1973). Questionamos a psicanálise e suas instituições. Petrópolis, RJ: Vozes.

Langer, M. (1977). Psicanálise institucional e psicanálise sem instituição. Belo Horizonte, MG: Interlivros.

Lapassade, G. (1980). Socioanalisis y potencial humano. Barcelona: Espanha: Gedisa.

Pichon-Rivière, E. (1986). O processo grupal. São Paulo, SP: Martins Fontes.

Rodrigues, H. B. C. (2001). Um Robespierre rio-platense e um Danton Tupiniquim? Episódios da análise institucional no Rio de Janeiro. In A.M. Jacó-Vilela, A.C. Cerezzo \& H.B.C. Rodrigues (orgs.) Clio-Psyché hoje. Fazeres e Dizeres psi na história do Brasil (pp. 153-170). Rio de Janeiro, RJ: Relume Dumará/FAPERJ.

Rodrigues, H.B.C. (2002). No Rastro dos Cavalos do Diabo. Memória e história para uma reinvenção de percursos do paradigma do grupalismo-institucionalismo no Brasil. Tese de Doutorado, Universidade de São Paulo, São Paulo, SP, Brasil.

Rodrigues, H. B. C. (2004). O homem sem qualidades. História oral, memória e modos de subjetivação. Estudos e pesquisas em psicologia, 2(2), 24-46. 
Rodrigues, H. B. C. (2007). Sejamos realistas, tentemos o impossível! Desencaminhando a Psicologia através da Análise Institucional. In A. M. Jacó-Vilela, A.A.L. Ferreira, \& F. Portugal. (Orgs.). História da Psicologia: rumos e percursos (pp.515563). Rio de Janeiro, RJ: Nau, 2 ed.

Rodrigues, H. B. C., \& Barros, R.D.B. (2003). Socioanálise e práticas grupais no Brasil: um casamento de heterogêneos. Psicologia clínica. 15(1), 61-74.

Rodrigues, H. B. C.; Fernandes, P. J., \& Duarte, M. G. S. (2001a). Breve história da constituição do grupo Plataforma Argentino. In A. M. Jacó-Vilela, A.C. Cerezzo, \& H. B. C. Rodrigues (Orgs.) Clio-Psyché hoje. Fazeres e Dizeres psi na história do Brasil (pp. 127-138). Rio de J aneiro: Relume Dumará/FAPERJ .

Rodrigues, H. B. C., Fernandes, P. J., \& Duarte, M. G. S. (2001b). Os psicanalistas argentinos no Rio de Janeiro: problematizando uma denominação. In A. M. Jacó-Vilela, A.C. Cerezzo, \& H. B. C. Rodrigues (Orgs.) Clio-Psyché hoje. Fazeres e Dizeres psi na história do Brasil (pp. 139-152). Rio de Janeiro, RJ: Relume Dumará/FAPERJ .

\section{Endereço para correspondência \\ Domenico Uhng Hur}

Universidade Federal de Goiás

Faculdade de Educação

Rua 235, s/n, Setor leste universitário, CEP 74605-050, Goiânia - GO, Brasil.

Endereço eletrônico: domenico@ufg.br

Recebido em: 23/09/2014

Aceito para publicação em: 24/09/2014

\section{Notas}

* Professor Adjunto do curso de Psicologia da Universidade Federal de Goiás. Psicólogo, mestre e doutor em Psicologia Social pelo Instituto de Psicologia da USP, com estágio doutoral na Universitat Autònoma de Barcelona/Catalunya. Membro do CRISE - núcleo de estudos e pesquisas Crítica, Insurgência, Subjetividade e Emancipação. Coordenador do curso de Psicologia (graduação) da UFG (Goiânia)

1 Este artigo é a versão traduzida ao português do artigo: Hur, D.U. (2014). Esquizoanálisis y Esquizodrama, clinica y política: presentación de la obra de Gregorio Baremblitt. Teoría y crítica de la psicología, vol. 4, pp. 1-16 (ISSN: 21163480).

2 Para a construção da história de Baremblitt, pesquisas da Profa. Heliana de Barros Conde Rodrigues sobre a história da Análise Institucional no Brasil, tal como sua tese de doutorado (Rodrigues, 2002), são fonte valiosa e inestimável. 